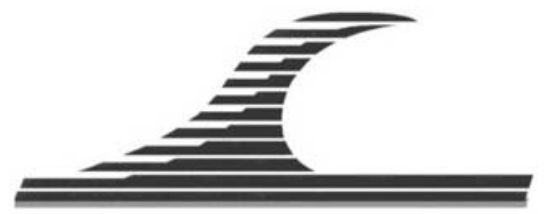

Revue Paralia, Volume 6 (2013) pp 3.1-3.12

Keywords: Sediment, Dredging, Biological impact, Deposits, Index for coastal infaunal assessing, Sustainable development.

(C) Editions Paralia CFL

\title{
Benthic quality evaluation of immersion zones of sediments dredging
}

\author{
Pascal GREGOIRE ${ }^{1}$, Nor Edine ABRIAK ${ }^{2}$, Samira BRAKNI $^{2}$, \\ Raouf ACHOUR ${ }^{2,3}$
}

1. Direction de l'Aménagement et de l'Environnement, Grand Port Maritime de Dunkerque, Terre-plein Guillain, BP 46534, 59386 Dunkerque Cedex 1, France. PGregoire@PortDeDunkerque.fr

2. Ecole des Mines de Douai, Département Génie Civil et Environnemental, 764 Boulevard Lahure, BP 10838, 59508 Douai, France.

nor-edine.abriak@mines-douai.fr ; raouf.achour@mines-douai.fr

3. Department of Civil Engineering, Université de Sherbrooke, Canada.

\begin{abstract}
:
Dredging operations pose the problem of sediment deposits to be evacuated by taking into account economic incidences and environmental aspects related to environmental protection. Coastal sediments are high biodiversity zones, where a multitude of living organisms have a special relationship with their substrate. An addition of exogenous materials has an impact on the natural equilibrium of the environment, notably during the transfer of contaminants on immersion zones, affecting species and the ecosystem. The objective of environmental assessment process is to estimate the potential risk of exposure upon ecosystems by integrating the benthic communities assessment. The evaluation of biological impacts in immersion zones helps to apprehend better the risk of using operational tools of appreciation.

The aim of this paper is to present an expertise approach based upon index for assessing coastal endofauna. This index makes it possible to know sediment biological quality by making more transparent the environmental assessment process potentially influencing the deposits method and the monitoring of dredging operations in a sustainable development context. Study results show that sediments immersion effect is low and has a short duration on immersion zones having strong currents allowing rapid sediments resuspension.
\end{abstract}

\footnotetext{
Received 13 January 2011, accepted 25 March 2013, available online 22 April 2013. The reviewing procedure concerns the version written in English. The version written in any other language is published under the sole responsibility of the author(s). UNE VERSION TRADUITE EN FRANCAIS EST DIPONIBLE EN LIGNE
}

How to cite this paper:

GREGOIRE P., ABRIAK N.E., BRAKNI S., ACHOUR R. (2013). Benthic quality evaluation of immersion zones of sediments dredging. Revue Paralia, Vol. 6, pp 3.1-3.12.

DOI:10.5150/revue-paralia.2013.003 (disponible en ligne - http://www.paralia.fr - available online) 


\section{Introduction}

The majority of harbour sites are located in sheltered zones. The importance of sedimentary phenomena related to hydrodynamic conditions of tides, currents, waves and wind cause siltation conditions. This sedimentation of suspended solids is continental or marine and constitutes an obstacle to vessel access to harbour infrastructures. Harbour activity has a strategic role for the national or international economy and many harbours carry out dredging works leading to evacuate large volumes of sediments in order to ensure access of commercial navigation to the channels, the outer harbour and basins. The annual quantities immersed in Europe represent about 185 million tons, with only 5 countries (Belgium, Germany, United Kingdom, France and the Netherlands) providing more than $90 \%$ of the deposits of dredged materials. These practices are indispensable to harbours activities for maritime safety reasons; nevertheless new concerns based on environmental protection show that some operations are problematic because of potential impacts on aquatic environments. Their protection is developed both in national and international regulations. Environmental problems are a major concern and most countries henceforth base their environmental national policy on the concept of sustainable development. Dredging is necessary, because of the economic impact that would result from the obstacles to navigation but this practice should only be continued if the constraints on coastal ecosystems preservation are taken into account. Indeed, immersions are a pathway for the transfer of contaminants into the marine environment and make dispositions to limit the impact on ecosystems should be taken (ALZIEU, 1999).

OSPAR guidelines (OSPAR, 1998) on the management of dredged sediments define surveillance as the measurements taken allowing on the one hand to ensure that the imposed prescriptions are respected at the time of issuance of the immersion permit; on the other hand, to verify the changes observed over immersion zones corresponding to the impact hypothesis based on the issuance of the permit. The surveillance strategy applied to Dunkirk harbour is based on the verification of impact hypothesis within the context of an ascending approach satisfying the guidelines. In order to assess the environmental quality, sediments were collected from immersion zones to make physicochemical (sediment grain size distribution, geochemical analysis) and biological analysis. These analyzes are used to calculate some indices (species richness and density, Shannon index, equitability and Evaluation Index of Coastal Infaunal).

\section{Methodology}

The methodology is based on detecting signs of ecosystem disturbance by the analysis of sediment-dwelling populations and on the response of these populations to the changes induced by dredged materials immersion. The composition and structure of soft bottoms population are used to characterize the environmental conditions and estimate potential impacts on the benthos. The evaluation method is quantitative and based on 
the distinction in the macrofauna of five species groups having in common a similar sensitivity towards excess organic matter and with a possible oxygen deficit resulting from its degradation. The ecological groups are composed of species which have a different sensitive to pollution and are considered as biological indicators:

a) Group I: species susceptible to hypertrophization, they are the first to disappear when there is an environmental enrichment. They are suspension feeders, selective carnivores and some species which feed on organic matter like subsurface tubicoles.

b) Group II: species indifferent to hypertrophization and little influenced by an increase of organic matter content, they are mainly carnivorous and not very selective necrophagous species.

c) Group III: species tolerant to hypertrophization and naturally present in silt. Their proliferation is stimulated by environmental enrichment and their presence is a sign of system disequilibrium. They are species which feed on organic matter, tubicolous or not, taking advantage of the organic matter charged bed surface.

d) Group IV: second-order opportunistic species. They are small species with a short cycle ( $<1$ year) abundant in polluted zones having poor sediments. They are subsurface deposit feeders.

e) Group V: first-order opportunistic species. They are deposit feeders proliferating in poor sediments throughout their thickness up to the surface.

The Evaluation Index of Coastal Infaunal (EICI) is therefore based on the distinction in benthic macrofauna of five species groups sharing similar sensitivity to the excess of organic matter and with the possible deficit of oxygen resulting from its degradation. Each species is thus affected to an ecological group based on its sensitivity to increasing gradient of environmental stress (see figure 1).

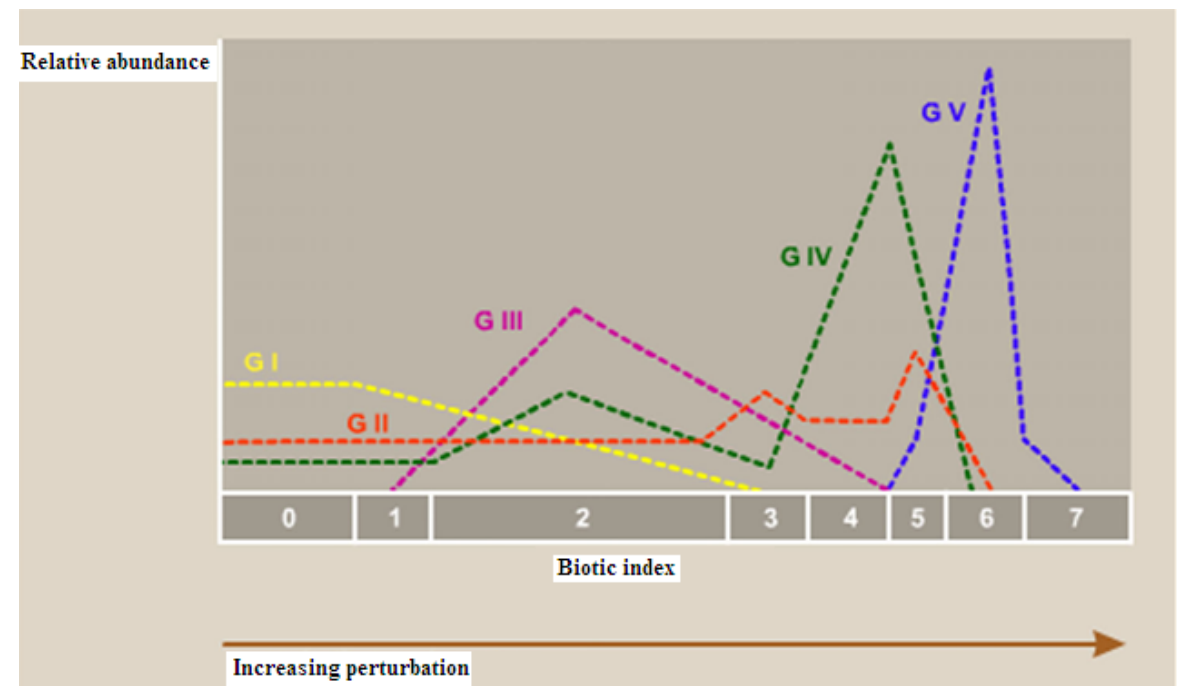

Figure 1. Groups distribution according to the organic pollution on the coast

(GLEMAREC, 2003). 
The index values are defined by the successive states of species assembly.

The evaluation model of EICI recognizes four main stages from the normal state of the population (EICI=0) where the sensitive species are dominant to the maximal pollution $($ EICI=6). This state is characterized by a few opportunistic species of first- order reaching exceptional densities (100 000 individuals $/ \mathrm{m}^{2}$ ) on the surface of poor sediments. Conditions of transition or ecotone (EICI=1, 3 and 5) exist between these four main stages. They are characterized either by an important reduction of parameters representing the species richness and populations abundance or on the contrary by the proliferation of one indifferent species, favoured by a lack of competition. Group II (indifferent species) is not taken into account in the table because this group can characterize ecotonal situations corresponding to index 3 and 5 (see table 1).

Table 1. Percentage of different ecological groups defining indices and environment quality (GRALL et al., 2003).

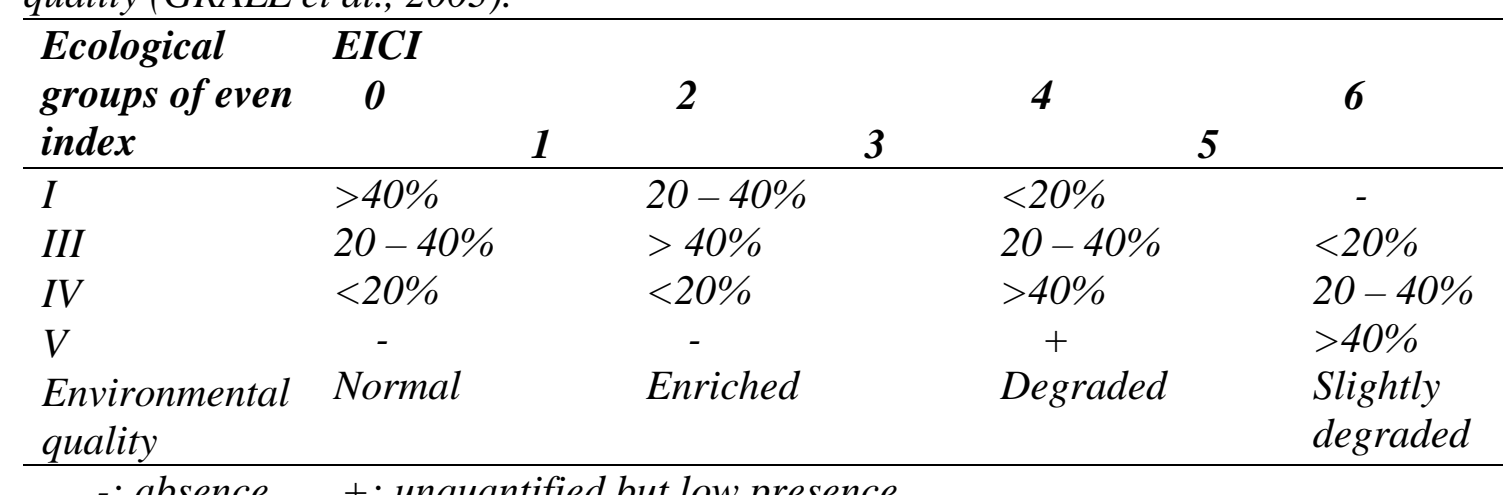

-: absence +: unquantified but low presence

\section{Sampling}

The study protocol considers a number of sampling stations described in table 2 . The stations were positioned using a metric differential GPS, delivering accuracy to within one metre, on a plotter, with SHOM charts in memory (figure 2). On each station, four strokes of Van Veen grab were made: 3 samples were used to constitute an average sample for benthic macrofauna analysis; the last one has been used for the physicochemical analysis in laboratory. The Van Veen grab allows sampling of $1 / 10 \mathrm{~m}^{2}$ of sediment at each stroke, in accordance with the "normalized" surface macrobenthos samplings protocol. For the loose subtidal sediment, the presence or absence of species is related to sediment nature, through the substratum grain size distribution. The grain size depends on sedimentation and its transport resulting from currents and water masses agitation. The sample is sieved with a meshing of $1 \mathrm{~mm}$ selecting only the sediment macrofauna. Living organisms are then recovered and conserved in $70^{\circ}$ alcohol in order to be identified in the laboratory under a binocular microscope. Data collected are then used to calculate the individuals number per species (biomass) and species richness (biodiversity); these two parameters are used to characterize populations and to 
refer to the occupation surfaces. Results can be represented as an ecological index (Shannon, evenness), branch diagrams and trophic index. The species will be correlated with sedimentary data.

Table 2. Samplings on the different zones of Dunkirk harbour (IN VIVO, 2006).

\begin{tabular}{llll}
\hline Immersion zone & Areas (ha) & Stations numbers & Stations codifications \\
\hline East harbour & 105 & 4 & $I V-1,2,3,4$ \\
Centre harbour & 88 & 4 & $I I I-1,2,3,4$ \\
North West Harbour & 130 & 4 & $I-1,2,3,4$ \\
South West Harbour & 147 & 4 & $I I-1,2,3,4$ \\
Control zone & 82 & 4 & $T-1,2,3,4$ \\
\hline
\end{tabular}

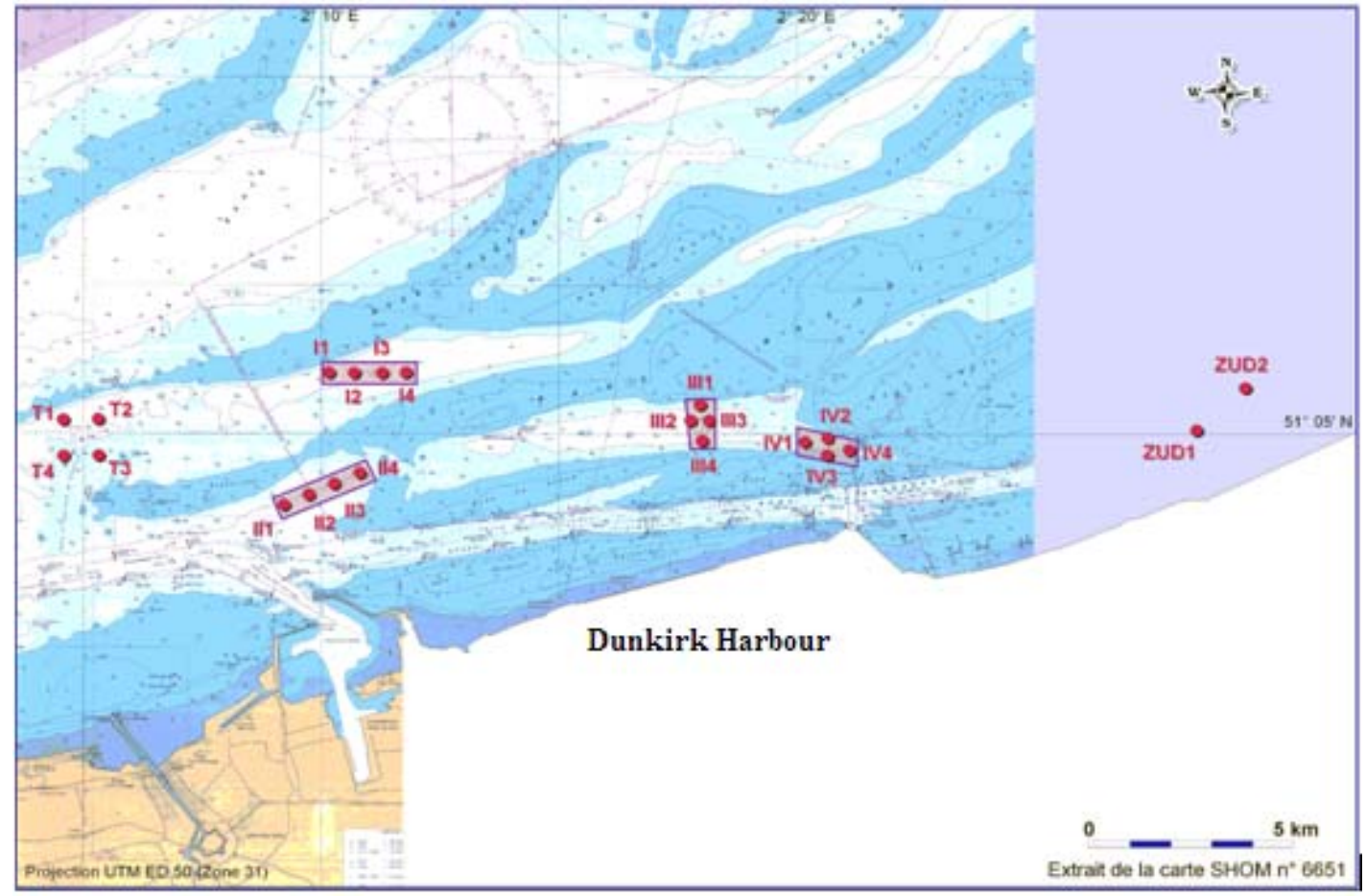

Figure 2. Sampling stations on immersion zones of Dunkirk harbour (IN VIVO, 2006).

\section{Sediments grain size distribution}

The grain size distribution by laser diffraction is used to classify sediments (see table 3). The IV-2 sample presents almost identical silt and sands content. The I-2 and IV-1, 3, 4 samples correspond in majority to fine sand, while I-1, 3, 4 and III-1, 2, 3, 4 and T-1, 2, 3, 4 samples correspond to medium sand with a majority of coarse sands. Some samples present significant silt content higher than 12\%: it concerns I-2, III-1, 4 and IV - 1, 2, 4 samples. 
Table 3. Summary of particle size results (except untreated samples II).

\begin{tabular}{llllll}
\hline Samples & \% Silt & \% Fine sand & \% Medium sand & Mode $(\boldsymbol{\mu m})$ & Median $(\boldsymbol{\mu m})$ \\
\hline$I-1$ & 1.07 & 17.81 & $\mathbf{8 1 . 1 2}$ & 390.9 & 387.4 \\
$I-2$ & 22.83 & $\mathbf{4 5 . 9 3}$ & 31.24 & 269.2 & 232.6 \\
$I-3$ & 2.59 & 12.32 & $\mathbf{8 5 . 0 9}$ & 390.9 & 425.8 \\
$I-4$ & 5.53 & 39.99 & $\mathbf{5 4 . 4 8}$ & 295.5 & 293.1 \\
$I I I-1$ & 35.75 & 19.18 & $\mathbf{4 5 . 0 7}$ & 429.2 & 226.1 \\
$I I I-2$ & 2.96 & 27.93 & $\mathbf{6 9 . 1 1}$ & 324.4 & 351.8 \\
$I I I-3$ & 3.86 & 27.65 & $\mathbf{6 8 . 4 9}$ & 324.4 & 349.9 \\
$I I I-4$ & 12.53 & 46.94 & 50.53 & 245.2 & 253.1 \\
$I V-1$ & 13.15 & $\mathbf{7 6 . 9 6}$ & 9.89 & 185.4 & 186.3 \\
$I V-2$ & $\mathbf{4 2 . 5 7}$ & 33.80 & 23.63 & 203.5 & 134.6 \\
$I V-3$ & 1.39 & 59.31 & 39.30 & 245.2 & 259.9 \\
$I V-4$ & 15.89 & $\mathbf{7 0 . 9 9}$ & 13.12 & 223.4 & 201.3 \\
$T-1$ & 1.11 & 18.82 & $\mathbf{8 0 . 0 7}$ & 295.5 & 492.6 \\
$T-2$ & 1.12 & 21.55 & $\mathbf{7 7 . 3 3}$ & 390.9 & 402.1 \\
$T-3$ & 0.96 & 25.82 & $\mathbf{7 3 . 2 2}$ & 356.1 & 354.0 \\
$T-4$ & 0.71 & 8.08 & $\mathbf{9 1 . 3 5}$ & 489.2 & 81.4 \\
\hline
\end{tabular}

\section{Geochemical analysis}

The organic pollution is evaluated through three parameters, total organic nitrogen (TKN), total phosphorus (P) and total organic carbon (TOC) classified with indices from 0 to 4 affected to each parameter value according to the contamination level of micropollutants and reflecting the organic pollution (see table 4). The organic pollution is the sum ranging from 0 to 11 of three contamination indices calculated with the value for each parameter analyzed in the sample. The results of sediments analysis for each sample and for each parameter permit to define the organic pollution for each studied station (see table 5).

The analyzed sediments are low in nitrogen, carbon and phosphorus with the exception of III-1 and IV-2 samples rich in carbon (6.2 and 7.2) and whose contents in silt are the greatest (35.75\% and $42.57 \%)$.

Table 4. Contamination indices definition of the organic pollution.

\begin{tabular}{llll}
\hline $\begin{array}{l}\text { Total Organic } \\
\text { Carbon (TOC) }\end{array}$ & $\begin{array}{l}\text { Total Organic } \\
\text { Nitrogen }(\mathbf{N T K})\end{array}$ & $\begin{array}{l}\text { Total Phosphorus } \\
(\boldsymbol{P})\end{array}$ & $\begin{array}{l}\text { Contamination } \\
\text { Indices }\end{array}$ \\
Values $(\mathbf{g} / \mathbf{k g}$ dry) & Values $(\mathbf{g} / \mathbf{k g}$ dry) & Values $(\mathbf{g} / \mathbf{k g}$ dry) & $\mathbf{0 - 4}$ \\
\hline$<0.6$ & $<600$ & $<500$ & 0 \\
$0.6-2.3$ & $600-1200$ & $500-800$ & 1 \\
$2.4-4$ & $1200-2400$ & $800-1200$ & 2 \\
$4.1-5.8$ & $2400-3600$ & $>1200$ & 3 \\
$>5.8$ & $>3600$ & $/$ & 4 \\
\hline
\end{tabular}


Table 5. Geochemical analysis of samples (IN VIVO, 2006).

\begin{tabular}{llllll}
\hline Samples & Density & TOC & NTK & $\boldsymbol{P}$ & $\begin{array}{l}\text { Organic } \\
\text { Pollution }\end{array}$ \\
\hline$I-1$ & 1.94 & $<1.5$ & 0.07 & 0.26 & $0-1$ \\
$I-2$ & 1.65 & 3.8 & 0.36 & 0.30 & 2 \\
$I-3$ & 2.04 & 1.5 & 0.08 & 0.31 & $0-1$ \\
$I-4$ & 1.35 & $<1.5$ & 0.08 & 0.25 & $0-1$ \\
$I I I-1$ & 1.77 & 6.2 & 0.65 & 0.96 & 4 \\
$I I I-2$ & 1.99 & $<1.5$ & 0.19 & 0.38 & $0-1$ \\
$I I I-3$ & 1.64 & $<1.5$ & 0.10 & 0.31 & $0-1$ \\
$I I I-4$ & 1.87 & 1.9 & 0.17 & 0.31 & $0-1$ \\
$I V-1$ & 1.92 & 2.6 & 0.39 & 0.29 & 2 \\
$I V-2$ & 1.59 & 7.2 & 0.78 & 0.44 & 4 \\
$I V-3$ & 1.44 & $<1.5$ & 0.06 & 0.19 & $0-1$ \\
$I V-4$ & 1.70 & $<1.5$ & 0.30 & 0.32 & $0-1$ \\
$T-1$ & 2.01 & $<1.5$ & 0.07 & 0.29 & $0-1$ \\
$T-2$ & 1.95 & $<1.5$ & 0.08 & 0.35 & $0-1$ \\
$T-3$ & 2.10 & $<1.5$ & 0.06 & 0.27 & $0-1$ \\
$T-4$ & 2.06 & $<1.5$ & 0.08 & 0.19 & $0-1$ \\
\hline
\end{tabular}

\section{Biocenosis analysis}

The ecosystem is defined by the descriptive and physical part of the environment, called biotope, and by the biological part, named biocenosis. It forms a complex dynamic system, in equilibrium, which works by inflows and outflows of energy from currents and sedimentary matter transport, and from a biological activity called ecosystem. The species location and populations distribution depends on biotope and habitat nature with its physical conditions. The benthic communities are an extremely important link in marine ecosystem. The benthos is an essential integrator for understanding the effects of human activities on the environment. This type of fauna, whose movements are restricted, is directly dependent on the environment quality and thus constitutes an environment quality indicator. The different factors related to the megatidal system, to the hydrography influence, to the geological structures variation and anthropogenic inputs allowed to distinguish five major biosedimentary units in the Eastern English Channel and the North Sea:

a) the gravel population with epibiosis sessile, a typical characteristic of zones with strong currents on marine of coarse gravel bed (80\%), gravel (10-15\%) and sand;

b) the gravel population with Amphioxus lanceoatus on gravel sediments (40-50\%), clean coarse sands (10\%) and medium to fine sands without pelites;

c) the silty heterogeneous population on pelites sediment (4\%), pebbles (10-30\%), gravels (5-10\%), sands (30-50\%) typical of North Sea; 
d) the fine to medium sands population specific to Ophelia borealis on fine and medium sandy sediment (60-90\%) without pelites;

e) the silty fine sand populations of Abra alba on sediment of fine sands (over 60\%) with variable pelitic fraction (1-30\%).

The biocenosis analysis was obtained from the quantitative and qualitative faunal list of collected species at each station.

The evaluation method remains quantitative, it is based on ecological groups composed of different species sensitive to pollution that allow us to establish the biological indicator. In the context of port management, this approach is used in order to obtain an expected estimate of the environmental degradation and to have an overall response of risks due to pollution.

\subsection{Species richness and density}

Species richness (counted species) and density (number of individuals per area unit) define the population structure in front of studied stations (see table 6).

Table 6. Species richness and density of different stations (IN VIVO, 2006).

\begin{tabular}{ccc}
\hline Samples & Species richness & Density (individuals $\mathbf{m}^{\mathbf{2}}$ ) \\
\hline$I-1$ & 3 & 43 \\
$I-2$ & 7 & $\mathbf{2 0 3}$ \\
$I-3$ & 5 & 23 \\
$I-4$ & 8 & 123 \\
$I I-1$ & 10 & $\mathbf{8 7}$ \\
$I I-2$ & 2 & $\mathbf{2 7}$ \\
$I I-3$ & 2 & $\mathbf{1 0}$ \\
$I I-4$ & 1 & $\mathbf{1 0}$ \\
$I I I-1$ & 4 & $\mathbf{2 3}$ \\
$I I I-2$ & 6 & 50 \\
$I I I-3$ & 4 & 43 \\
$I I I-4$ & 10 & 147 \\
$I V-1$ & 7 & 73 \\
$I V-2$ & 12 & $\mathbf{1 9 0}$ \\
$I V-3$ & 2 & $\mathbf{1 0}$ \\
$I V-4$ & 8 & 183 \\
$T-1$ & 4 & 27 \\
$T-2$ & 6 & 53 \\
$T-3$ & 6 & 47 \\
$T-4$ & 5 & 50 \\
\hline Species richness $i s$ high when the number of species exceeds 20
\end{tabular}

Species richness is high when the number of species exceeds 20. 
For the studied samples, species richness is medium $(<20)$ for II-1, III-4, IV-2 and low $(<10)$ for the other stations.

Comparatively, the reference zone species richness is equivalent to that of other zones with a similar grain size distribution. Samples present a greater species richness when the fine sediment content is high. Densities of about 10 to 203 individuals $/ \mathrm{m}^{2}$ are relatively low but coherent with this environment (gravels bed and important currents) and confirm the heterogeneity between different stations.

Benthic expertise shows in variable proportion four species regularly present in samples (annelid Nephtys cirrhosis and Nephtys hombergii, the bivalve Abra alba and the crustacean Bathyporeia elegans).

The observation of species richness distribution in the different groups reveals:

a) a heterogeneous zone I;

b) a zone II dominated by bivalves (Abra alba);

c) a zone III dominated by annelid (Nephthys cirossa) and echinoderms (Gastrosaccus spinifera);

d) a zone IV where the annelid species are dominant (Nephthys sp);

e) a homogeneous reference zone where the species number of crustaceans (Bathyporeia sp) is high and the species number of bivalves and annelids similar.

In terms of density and species richness, the dredged sediments of the immersion zones are heterogeneous with densities and species richness highly variable on the same zone; values increase when the fine grains are more important in the samples.

The reference zone is homogeneous with low values of species richness and density at each station.

\subsection{Shannon index}

The evaluated diversity using the Shannon index takes into account both species number and their respective individual number. The more the distribution is equitable between species, the more the diversity is important, meaning an equilibrium state of population. The existence of a disturbance causes a population disequilibrium expressed by the proliferation of small number of species to the detriment of other populations and thus by an important decrease in diversity.

The population is in equilibrium when the Shannon index is at least equal to 3 . For the studied samples, the Shannon index varies from 0.54 (station III-1) to 3.09 (station IV2) according to the representation of figure 3. The highest values (index greater to 2.6) are associated with the highest values of species richness and density, revealing a population relatively in equilibrium (I-4, II-1, III-4 and IV-2 stations). The low index values are associated with the low values of species richness and density expressing that population is dominated by one species (station IV-4, annelid Nephtys homberg) or presenting very low species richness (II -4, one species). 


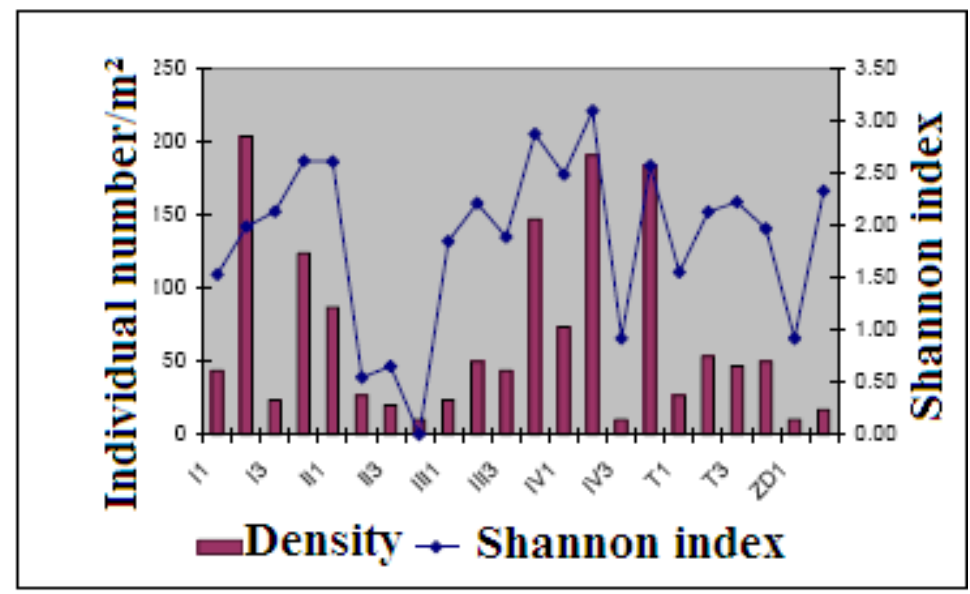

Figure 3. Shannon index and density of different stations (IN VIVO, 2006).

\subsection{Equitability}

Equitability presents the population equilibrium state and permits a comparison between all stations without considering the total number of present species. This parameter varies between 0 and 1, depending on whether the population is more or less balanced. Most stations have a relatively high equitability around 0.8 which tends to demonstrate that there is no significant disequilibrium. This value must be relativized because only few species are present in the samples.

\subsection{EICI index}

The index presents the environment quality according to ecological groups in the sample. The result of this index is nevertheless to be minimized because the populations are relatively poor and the immersion zones are under the influence of strong tidal currents contributing to zones modification and populations instability.

Table 7 assesses the environment quality state by using the EICI index according to different ecological groups on the different zones.

In the case of reference zone (T), the index indicates that the area is enriched whereas there is no input of harbour sediments.

Table 7. Environmental quality of studies areas.

\begin{tabular}{|c|c|c|c|c|c|c|c|}
\hline \multirow[t]{2}{*}{ Zones } & \multicolumn{5}{|c|}{ Ecological groups (\%) } & \multirow{2}{*}{$\begin{array}{l}\text { EICI } \\
\text { index }\end{array}$} & \multirow{2}{*}{$\begin{array}{l}\text { Areas } \\
\text { quality }\end{array}$} \\
\hline & $I$ & II & III & $I V$ & $V$ & & \\
\hline$I$ & 44.7 & 10.6 & 44.7 & 0 & 0 & 2 & Enriched \\
\hline II & 3.8 & 7.6 & 88.5 & 0 & 0 & 3 & Enriched \\
\hline III & 58.6 & 17.2 & 24.2 & 0 & 0 & 0 & Normal \\
\hline$I V$ & 18.8 & 30.1 & 43.6 & 0 & 0 & 3 & Enriched \\
\hline$T$ & 35 & 65 & 0 & 0 & 0 & 2 & Enriched \\
\hline
\end{tabular}




\subsection{Zones characterization}

a) Zone I shows low species richness and a highly variable density of individuals per $\mathrm{m}^{2}$. The population seems similar to the population of fine to medium sands appropriate to Ophelia borealis.

b) Zone II indicates a population that does not match an identified biocenosis unit. This population badly defined is dominated by the bivalve Abra alba. A sample (II-1) presents characteristic species of heterogeneous silted population. The eutrophication tolerant species being very abundant, the environment is enriched.

c) Zone III is characteristic of populations with fine to medium sands specific to Ophelia borealis. The proportion of sensitive species (group I) is higher than that of the tolerant species (group III).

e) Zone IV is heterogeneous in specific richness and density of individuals per $\mathrm{m}^{2}$. The population is assimilated to the silty fine sands population of Abra alba; the population is enriched with not insignificant presence of tolerant species.

d) Zone $\mathrm{T}$ (reference) indicates a specific richness and a low abundance with small homogeneous populations, characteristics of a population of fine to medium sands, specific of Ophelia borealis. According to the index, the environment is enriched because species of groups I and II are in equal proportions.

In general, the populations collected in the different zones are poor but coherent with environmental conditions. The presence of strong currents is not conducive to the mass installation of species. The immersion effects are low and have a short duration on the concerned zones in relation with the strong currents causing a rapid remobilization of sediments.

\section{Conclusions}

This paper presents an experience feedback concerning the use of a coastal infauna evaluation index. This index allows to highlight the biological quality of sediments in order to improve the control of environmental risk assessment, the monitoring of dredging operations and the harbour sediments stockpiling. The approach is based on detecting signs of ecosystem disturbance by the analysis of sediment-dwelling populations. The population reactions to the changes induced by the immersion of dredged material characterize the environment conditions and estimate potential impacts on benthos. Particle size analysis results show that most samples are made up of medium to coarse sand. Fine sand proportion is a majority in only 4 samples. The percentage of sand and silt is almost identical in one sample. Samples with high levels of silt are poor in nitrogen, carbon and phosphor except for two samples (III-1 and IV2). The immersion zones of dredged sediments are heterogeneous, with species densities and species richness highly changing on the same zone. Values increase when fine grains are more present in a sample. The reference zone is homogeneous with low values of species richness and species density at each station. The high values obtained 
from the Shannon index show that some samples (I-4, II-1, III-4 and IV-2) have a balanced population. The lowest values show that the population is dominated by a species (sample IV-4) or has very low species richness (II-4, one species). The populations present in the immersion zones are low but coherent with environmental conditions. Strong currents are not favorable for the massive installation of species. The evaluation method is quantitative and is based on ecological groups composed of different species sensitive to pollution regarded as biological indicators. The biotic characterization results favour a proactive approach of expertise of potential biological effects on the marine environment. This orientation contributes to an environmental assessment process promoting the legitimacy of the immersion of sediment or allowing to study alternative solutions in order to protect the aquatic ecosystems and constitute a real challenge for sustainable development.

These two methods serve to evaluate and correlate the quantity of benthos: in fact, the use of the ecotoxicity method allowed us to estimate the foreseeable risk of degradation of the natural environment and gives us a comprehensive response to pollution (risk or no risk), on the other hand the physicochemical tests allow us to justify ecotoxicity and the potential impact on the natural environment. The use of physico-chemical approach requires the measurement of many substances by sampling, this approach is more expensive than the ecotoxicity approach. To evaluate the environmental risk, the coupling of the two methods makes the scientific approach concerning risk assessment of environmental degradation more reliable.

The results of this work announce also prospects of complementary research, with a priority concept based on contaminants bioaccumulation in the tissues of living matter; in order to assess on the immersion zone environment the influence of repetitive sediments depositing and to assess the potential impact on marine environment and the sanitary risk induced.

\section{References}

ALZIEU C. (1999). Dragages et environnement marin. Etat des connaissances : comportement des polluants. Institut français de recherche pour l'exploitation de la mer, $223 \mathrm{p}$.

GRALL J., QUINIOU F., GLEMAREC M. (2003). Bioévaluation de la qualité environnementale des milieux portuaires. Institut français de recherche pour l'exploitation de la mer, $247 \mathrm{p}$.

GLEMAREC M. (2003). Les indices biotiques en milieu sédimentaire. Institut français de recherche pour l'exploitation de la mer, $247 \mathrm{p}$.

IN VIVO (2006). Rapport d'évaluation de l'endofaune côtière sur les zones d'immersion du Port Autonome de Dunkerque.

OSPAR (1998). Lignes directrices sur la gestion des matériaux de dragage. MMC

98/8/5- F Ospar Commission, London 40 p. 